\title{
Correction to: Overlapping genetic architecture between Parkinson disease and melanoma
}

\author{
Umber Dube ${ }^{1,2,3,4} \cdot$ Laura Ibanez $^{2,4} \cdot$ John P. Budde ${ }^{2,4} \cdot$ Bruno A. Benitez $^{2,4} \cdot$ Albert A. Davis $^{3} \cdot$ Oscar Harari ${ }^{2,4}$. \\ Mark M. Iles ${ }^{5}$. Matthew H. Law ${ }^{6} \cdot$ Kevin M. Brown ${ }^{7} \cdot 23$ andMe Research Team • Melanoma-Meta-analysis \\ Consortium $\cdot$ Carlos Cruchaga ${ }^{2,3,4}$ (1)
}

Published online: 14 March 2020

(c) Springer-Verlag GmbH Germany, part of Springer Nature 2020

\section{Correction to: Acta Neuropathologica (2020) 139:347-364 https://doi.org/10.1007/s00401-019-02110-z}

The original version of this article unfortunately contained a mistake. Supplementary Tables 3 and 4 are not available with the rest of the supplementary material available online.

These are included here.

Publisher's Note Springer Nature remains neutral with regard to jurisdictional claims in published maps and institutional affiliations.

Electronic supplementary material The online version of this article (https://doi.org/10.1007/s00401-020-02143-9) contains supplementary material, which is available to authorized users.

The original article can be found online at https://doi.org/10.1007/ s00401-019-02110-z.

Carlos Cruchaga cruchagac@wustl.edu

1 Medical Scientist Training Program, Washington University School of Medicine, 660 S. Euclid Ave, St. Louis, MO 63110, USA

2 Department of Psychiatry, Washington University School of Medicine, 660 S. Euclid Ave. CB8134, St. Louis, MO 63110, USA

3 Department of Neurology, Washington University School of Medicine, St Louis, MO, USA
4 Department of Psychiatry, NeuroGenomics and Informatics, Washington University School of Medicine, 660 S. Euclid Ave. B8111, St. Louis, MO 63110, USA

5 Leeds Institute for Data Analytics, University of Leeds, Leeds, UK

6 Statistical Genetics, QIMR Berghofer Medical Research Institute, Brisbane, Australia

Division of Cancer Epidemiology and Genetics, National Cancer Institute, National Institutes of Health, Bethesda, Maryland, USA 